\title{
Development of Instruments Batting in Softball with Live Pitching Implementation for Students
}

\author{
Oom Rohmah*, Agus Gumilar, Burhan Hambali, Salman Salman \\ Departemen Pendidikan Olahraga dan Kesehatan, Fakultas Pendidikan Olahraga dan Kesehatan \\ Universitas Pendidikan Indonesia \\ Bandung, Indonesia \\ *oomrohmah123@gmail.com
}

\begin{abstract}
This study aims to develop a hit skill test instrument in a softball game through the application of live pitching tools. The application of a live pitching sensor instrument in the development of a hit skill test instrument for students has never been done in Indonesia. The data from the live pitching evaluation can be a reference to be used as a benchmark in the development of a skill-hit test in softball games for college students. This research will use the Research \& Development method that refers to the procedures or stages developed by Morrow at.al (2005) that divide into 10 stages of instrument development Research will be conducted on students who follow softball FPOK Universitas Pendidikan Indonesia. Sample or research subject is taken from the whole population, using saturated sampling technique. The analysis done is (1) content validity estimation (Lawshe's CVR), (2) validity criterion (concurrent validity) by using PPM correlation analysis technique (person product moment), (3) test and retest reliability (PPM correlation). Based on the result of expert judgment valuation analysis and estimation value of instrument reliability coefficient of skill test based on live fetching, it can be concluded that overall the instrument has been developed and developed is feasible and reliable, result analysis reliability testing obtained value of reliability coefficient 0.72 . On the basis of these researchers can conclude that the instruments that have been developed can be used to measure the ability of students in assessing basic skills hit in the softball game on the student. In addition to the value of estimation value of reliability, the main basis in the feasibility of the instrument is the assessment of experts stating that the instrument is feasible and can be used to measure the beat skills in softball games.
\end{abstract}

Keywords-component; formatting; instruments test; live pitching batting softball test

\section{INTRODUCTION}

The softball game is a game played by two teams, each team consists of nine people and can also be added with $\mathrm{DH}$ (Designated Hitter) batter, the duration of softball game is determined by the inning, each team will get seven turns to guard and seven times become a team of attackers. Softball games have the characteristics of fast and precise game, quickly means any player either from the team of attackers or squads survivors are required to always think quickly in taking a decision or action in case of an event in a game. In addition to fast, accuracy is an important element to be considered. Every defender is required to do a quick and appropriate throw to kill the runner, if the guard is throwing is not fast and not exactly likely to turn off the runner will be difficult even if the throw error (an error) can happen extra base where the runner to the next base easily even can make run. Also in the batting of the attacker's team, besides having to be fast and strong in swinging the batter, a batter must be able to hit with the proper performant between the bat with the ball so as to produce a good punch. Spanking is one of the skills that is quite difficult because we have to hit a pitcher pitch whose ball direction is always changing especially with high pitcher speed makes it difficult to hit, which is similar to what is expressed "hitting has been called one of the most difficult skills in all of sport. If you are successful a third of the time, you would be considered very talented, one of the best in the game" [1]. The world of sports education is included in the school's learning curriculum incorporated in small ball game subjects. In lectures in PJKR FPOK UPI game is known by the name of softball game. Seeing the development of softball game that is growing then needed a measuring instrument or instrument that can measure the skill, because in learning test and measurement is one thing that is very important to be able to see how far the development of learning has been achieved, as expressed by Suntoda that: and measurement is an activity or an integral part in the process of assessing student learning outcomes. To measure the beat skills in the softball game there are two types of commonly used instruments: Fungo Batting test from O'Doniel and Hitting Productivity Tests from PB Perbasasi. But there are some obstacles to performing these two tests, the first is to test the productivity of hitting when performing the required test pitching machine which is very expensive equipment, not every agency or association has this tool. The fungo batting test according to the analysis of the researcher does not show the performance of a batter because the tester does the blow by itself without a pitcher, whereas in a softball game a batter must hit the ball of the pitcher.

Based on the above background explanation, the researcher wanted to update the skill test in softball game through the application of live pitching and application of zeep swinger analysis sensor for students and high school.

\section{METHOD}

Research conducted is Research and Development that is by doing the development of skill tests hit in softball game with 
the application of live pitching and zeep swing sensors to students. Research method is a way to obtain data, analyze and conclude the research results. The main purpose of this study was to seek validity and reliability of the hit skill test with the application of live pitching and zeep swing sensor analysis.

The purpose of developing this instrument is to acquire one hit skill instrument on a live fetching based softball game to measure student skills. In addition, the estimated validity and reliability values will be the focus of subsequent development in the development outcomes of this instrument. As has been pointed out in the previous discussion that content validity testing is one of validity testing in the process of developing the instrument, especially in the development of the skill assessment instrument hit on the softball game. In testing the content validity of the test item is valid if the items developed can accurately measure indicators, materials, or learning objectives that have been established and assessed by experts in certain fields [2]. The analytical technique used in testing the content validity in the interest of this research is the Content of the Risk validity of Lawshe.

\section{RESULTS AND DISCUSSION}

The results of the content validity analysis using Lawshe's CVR technique, the ratio of validity ranges from 0.60 to 1.00 , the lowest ratio obtained shows that there is one expert who states that the skill item is considered unimportant or too complicated when used. However, the ratio of 0.60 is still at the value of the ratio above the minimum value of 0.50 for testing the lawshe technique (CVR). Thus on items having a ratio value of 0.60 corrected in accordance with the advice of professional judgment which is then used in empirical testing, it is assumed because basically the ratio value obtained from the task items is above 0.50 . The results of the content validation test are then assessed by 10 students, the value of the ratio ranges from 0.60 to 1.00 , this means that the ratio value obtained is already qualified to be used as a skill item to measure hit skills. Based on the results of the analysis, all the coefficients of the content validity coefficient are greater than 0.50 therefore the items developed in the skill of hitting live pitching in softball games are validly valid in content, both assessed by academic experts and practitioners.

The results corroborate some theories that the content validity using CVR will be influenced by the number of assessors from the experts and the number of people who stated important in assessing the suitability of the item with the indicator. Ratio index ranges $-1 \leq \mathrm{CVR} \leq+1$ with criteria $\mathrm{Mp}$ $<1 / 2$ M CVR <0; Mp = 1/2M CVR = 0; Mp > 1/2 M CVR $>0$ [3]. Therefore, it is necessary to revise in accordance with the suggestions given by the experts, the suggestions concerning the accuracy of the contents of items that are based on indicators and accuracy of sentences that must be appropriate and can be better understood. Basically the suggestions are items re-revised and re-consulted until the experts declared fit and declared the item is valid on testing content validity. This corroborates the theory that in testing the content validity to be searched is the extent to which the items in the test cover the entire content area of the object to be measured [4].

Furthermore, the results of the expert analysis produced in this study support the results of other research and development such as [5]. Who conducted the qualitative test phase as the content validity stage using CVR analysis technique before continuing on empiric test. In addition, the results of the content validity ratio test proved to be conclusive with some of the results of research conducted [6]. However, other studies have found some differences in data analysis techniques after being reviewed and assessed by experts, including some of the results of research developed by instrument development [7]. Some of the results of this study using a technique of percentage analysis to assess the agreement of the experts after reviewing the instruments that have been developed so that the value of the agreement stretched between 0 to $100 \%$.

\section{CONCLUSION}

Based on the analysis of expert judgment assessment and estimation of the reliability coefficient of the Pitching-based hit skill test, it can be concluded that the overall instrument that has been compiled and developed is feasible, and reliable, reliability analysis results obtained reliability coefficient value of 0.72. On the basis of these researchers can conclude that the instruments that have been developed can be used to measure the ability of students in assessing basic skills hit in the softball game on the student. In addition to the value of estimation value of reliability, the main basis in the feasibility of the instrument is the assessment of experts stating that the instrument is feasible and can be used to measure the beat skills in softball games.

\section{REFERENCES}

[1] N. Rick, "Softball Fundamental," Human Kinetics, 2015

[2] N.K. Denzin, and Y.S. Lincoln, Handbook of Qualitative Research Edisi Bahasa Indonesia.Yogyakarta: Pustaka Belajar, 2009.

[3] B. Susetyo, Menyusun tes hasil belajar. Bandung: CV. Cakra, 2011.

[4] Fraenkel and Wallen, How To Design and Evaluate Reseach In Education. United State: Graw Hill, 1993.

[5] Y. Yudiana, Y. Hidayat, B. Hambali and S. Slamat, "Content Validity Estimation of Assessment Instrument Based on Volleyball Information System of Volleyball Learning: Field Research,” IOP Conference Series: Materials Science and Engineering, vol. 180, no. 1, pp. 012230, 2017.

[6] Smith, Burbank and Kenstrud, Field Measurements of Softball Player Swing Speed. Elsevier Ltd., 2012.

[7] M. Masato, Effects of baseball bat mass and position of center of gravity on batting. Elsevier Ltd., 2010. 